\title{
On the interpretation of the loading correction of the aethalometer
}

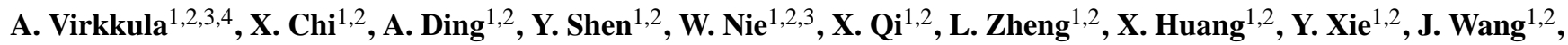 \\ T. Petäjä ${ }^{3}$, and M. Kulmala ${ }^{3}$ \\ ${ }^{1}$ Institute for Climate and Global Change and School of Atmospheric Sciences, Nanjing University, China \\ ${ }^{2}$ Collaborative Innovation Center for Climate Change, Jiangsu Province, China \\ ${ }^{3}$ Department of Physics, University of Helsinki, 00014, Helsinki, Finland \\ ${ }^{4}$ Finnish Meteorological Institute, Research and Development, 00560, Helsinki, Finland
}

Correspondence to: X. Chi (xuguang.chi@nju.edu.cn)

Received: 15 May 2015 - Published in Atmos. Meas. Tech. Discuss.: 17 July 2015

Revised: 6 October 2015 - Accepted: 9 October 2015 - Published: 21 October 2015

\begin{abstract}
Aerosol optical properties were measured with a seven-wavelength aethalometer and a three-wavelength nephelometer at the suburban site SORPES in Nanjing, China, in September 2013-January 2015. The aethalometer compensation parameter $k$, calculated with the Virkkula et al. (2007) method depended on the backscatter fraction, measured with an independent method, the integrating nephelometer. At $\lambda=660 \mathrm{~nm}$ the daily averaged compensation parameter $k \approx 0.0017 \pm 0.0002$ and $0.0042 \pm 0.0013$ when backscatter fraction at $\lambda=635 \mathrm{~nm}$ was in the ranges of $0.100 \pm 0.005$ and $0.160 \pm 0.005$, respectively. Also, the wavelength dependency of the compensation parameter depended on the backscatter fraction: when $b(\lambda=525 \mathrm{~nm})$ was less than approximately 0.13 the compensation parameter decreased with wavelength and at larger $b$ it increased with wavelength. This dependency has not been considered in any of the algorithms that are currently used for processing aethalometer data. The compensation parameter also depended on the single-scattering albedo $\omega_{0}$ so that $k$ decreased with increasing $\omega_{0}$. For the green light $(\lambda=520 \mathrm{~nm})$ in the $\omega_{0}$ range $0.870 \pm 0.005$, the average ( \pm standard deviation) $k \approx 0.0047 \pm 0.006$ and in the $\omega_{0}$ range $0.960 \pm 0.005$, $k \approx 0.0028 \pm 0.0007$. This difference was larger for the nearinfrared light $(\lambda=880 \mathrm{~nm})$ : in the $\omega_{0}$ range $0.860 \pm 0.005$, $k \approx 0.0055 \pm 0.0023$ and in the $\omega_{0}$ range $0.960 \pm 0.005$, $k \approx 0.0019 \pm 0.0011$. The negative dependence of $k$ on $\omega_{0}$ was also shown with a simple theoretical analysis.
\end{abstract}

\section{Introduction}

Aerosols affect both local, regional and global climate directly by scattering and absorbing solar radiation and indirectly by modifying cloud properties (e.g., IPCC, 2013). For the assessment of the direct radiative forcing it is crucial that both light scattering and absorption are measured accurately. Light-scattering measurements with the nephelometer are well established, but absorption is more difficult. An ideal method would make the measurement when the aerosol is in the suspended state. Such methods exist but the simplest, relatively cheap and therefore the most commonly used light absorption measurements are still based on collecting aerosols on a filter tape and detecting the reduction of light transmittance through the filter. Globally, probably the most widely used such filter-based method is the aethalometer, produced by Magee Scientific. It converts the reduction of light transmittance directly into black carbon (BC) mass concentrations by assuming that $\mathrm{BC}$ is the only aerosol component affecting the reduction and by assuming that the conversion is linear. The data are further used for calculating the light absorption coefficient $\left(\sigma_{\mathrm{a} p}\right)$. However, the calculation is not straightforward since light transmittance is not reduced only by the light-absorbing aerosols but also by scattering aerosols and by interactions between the filter fibers and accumulated aerosols. As a result, the BC mass concentration and the absorption coefficient $\sigma_{\mathrm{a} p}$ may be overestimated or underestimated. Algorithms have been developed to take these effects into account (e.g., Weingartner et al., 2003; Arnott et al., 2005; Schmid et al., 2006; Virkkula et al., 2007; Collaud 
Coen et al., 2010). An evaluation of the performance of these was presented by Collaud Coen et al. (2010).

The algorithm presented by Virkkula et al. (2007) corrects the $\mathrm{BC}$ mass concentration for the loading effect by multiplying the uncorrected concentrations by the function $f=1+k$ ATN where $k$ is the so-called compensation parameter and ATN is the attenuation reported by the aethalometer. As pointed out by Collaud Coen et al. (2010), it has problems: it only corrects for the loading effect and it is unstable because the variability of absorption coefficients is often higher than that induced by the filter changes. Another weakness of it is that the compensation parameter is calculated at the time of the change of the filter spot and applied for postprocessing the data of a whole filter-spot sampling period or even a longer period. This is one of the reasons leading also to the method instability pointed out by Collaud Coen et al. (2010). An algorithm that somewhat resembles that of Virkkula et al. (2007) is applied in the dual-spot aethalometer model in real time at high time resolution, so it removes the above-mentioned weakness (Drinovec et al., 2015). Cheng and Yang (2015) recently used two aethalometers at two different flow rates and processed the data with a method that is a modified version of that in the dual-spot aethalometer.

Despite the weaknesses, several authors have used the function $f=1+k$ ATN in post-processing their aethalometer data and also filter samples analyzed with a reflectometer (e.g., Heal and Hammonds, 2014). It has been observed in many studies that the value of $k$ varies with time and place. For example, Park et al. (2010) found different values for the $k$ in indoor and outdoor aerosol. Seasonal variation of it was presented already in the original paper: both at an urban site and at a rural site the factor was higher in winter than in summer (Virkkula et al., 2007). No good explanation was given; it was just hypothesized that it was due to the variation of the single-scattering albedo, which also has a seasonal cycle. A similar observation has also been made at other locations: for instance, in East Rochester, New York, USA (Wang et al., 2011), and at several sites in and around Beijing, China (Song et al., 2013), the $k$ factors were larger in winter than in summer. Also, Song et al. (2013) suggested this was probably due to darker aerosols in winter than in summer. It is definitely expected that the compensation parameter depends on the darkness, i.e., the single-scattering albedo of the particles, since the more detailed algorithms to calculate $\sigma_{\mathrm{a} p}$ from the aethalometer data take it explicitly into account (e.g., Schmid et al., 2006; Collaud Coen et al., 2010).

Also, the size of particles affects the absorption coefficients calculated from filter-based measurements. One of the reasons is that the penetration depth of the particles into the filter depends on their size and the depth affects the amount of light interactions with the particles (e.g., Arnott et al., 2005; Moteki et al., 2010; Nakayama et al., 2010). Lack et al. (2009) found that for particles larger than about $350 \mathrm{~nm}$ absorption measured with the Particle Soot Absorption Photometer (PSAP), another filter-based instrument, was signif- icantly underestimated, and concluded that the low bias was linked to the enhanced forward scattering from the larger particles. Müller et al. (2014) found that the asymmetry parameter - which is a function of the backscatter fraction - of the particles collected on the PSAP filter has significant effects on the derived $\sigma_{\mathrm{a} p}$. It is obvious that this should be true for the aethalometer also since these two instruments are so similar.

It was mentioned above that a site-related and seasonal variation of the value of the compensation parameter $k$ has been observed but no attempts for explaining it have been published. The new aethalometer model AE33 calculates and saves the compensation parameter at a high time resolution. Drinovec et al. (2015) presented even diurnal cycles of the compensation parameter measured with it but the interpretations were very qualitative. The goal of the present work is to study whether the backscatter fraction and single-scattering albedo could be the factors explaining the $k$ variations in past and new aethalometer measurements. The work is done by analyzing data measured at a field station in Nanjing, China. No independent absorption standard was available, so we do not even attempt to develop a new algorithm for calculating $\sigma_{\mathrm{a} p}$. Time series of scattering and absorption coefficients will be presented, but no analysis of the concentration levels, sources, transport, diurnal cycles or other related atmospheric processes will be presented here. They will be the contents of a related paper (Shen et al., 2015); the present paper concentrates on the interpretation of the compensation parameter.

\section{Measurements and methods}

\subsection{Measurement site and instruments}

The measurements were conducted at the SORPES station $\left(118^{\circ} 57^{\prime} \mathrm{E}, 32^{\circ} 07^{\prime} \mathrm{N}, 40 \mathrm{~m}\right.$ above mean sea level) in the $\mathrm{Xi}-$ anlin campus of Nanjing University. The station can be considered as an urban background station with little influence of local emissions (Ding et al., 2013a, b). The instruments used in this study take their sample air from two separate $\mathrm{PM}_{10}$ inlets. Drying of the sample air is done by heating the inlet lines. The temperature of the laboratory room where the instruments are located is kept constant with an air conditioner at approximately $20 \pm 5^{\circ} \mathrm{C}$ so when the outdoor conditions are warm and humid, the relative humidity of the sample air rises considerably. The relative humidity $(\mathrm{RH})$ of the sample air is measured with the RH sensor of the nephelometer. In this study only those data were used during which the RH was less than $50 \%$. When RH is higher, particles grow significantly, which affects all optical measurements. The World Meteorological Organization Global Atmosphere Watch (WMO/GAW) recommends for aerosol monitoring stations to keep the sample air RH at $45 \pm 5 \%$ (WMO, 2003). 


\subsubsection{Nephelometer}

Total scattering coefficients $\left(\sigma_{\mathrm{s} p}\right)$ and backscattering coefficients $\left(\sigma_{\mathrm{bs} p}\right)$ at $\lambda=450,525$, and $635 \mathrm{~nm}$ were measured with an ECOTECH Aurora 3000 nephelometer. The scattering and backscattering coefficients are presented at STP conditions (standard temperature and pressure, $273.15 \mathrm{~K}$, $1013.25 \mathrm{hPa}$ ). The flow to the nephelometer was provided by the internal pump of the instrument. The averaging time was set to $5 \mathrm{~min}$. The nephelometer was calibrated manually and zeros and spans were checked automatically according to the manual by using 1,1,1,2-tetrafluoroethane (R-134) as the calibration gas.

The raw total scattering coefficients were corrected for truncation errors by calculating first the Ångström exponents from the non-corrected scattering coefficients and then following the formulas presented by Müller et al. (2011) where the tabulated factors for no cutoff at the inlet were used. To be used in the aethalometer data processing the truncationcorrected $\sigma_{\mathrm{s} p}$ at the nephelometer wavelengths were interpolated and extrapolated to the aethalometer wavelengths assuming that the Ångström exponent of scattering was constant over the wavelength range.

The backscatter fractions $\left(b=\sigma_{\mathrm{bs} p} / \sigma_{\mathrm{s} p}\right)$ were calculated as the ratio of the backscattering coefficient and the truncation-corrected total scattering coefficients at the nephelometer wavelengths. The backscattering coefficients were neither interpolated nor extrapolated.

\subsubsection{Aethalometer}

A seven-wavelength aethalometer (AE-31) was used for measuring light absorption at $\lambda=370,470,520,590,660$, 880 , and $950 \mathrm{~nm}$. The aethalometer reports BC mass concentrations but from these data absorption coefficients were calculated as will be discussed below. The flow was provided by the internal pump, it was set to $5 \mathrm{~L} \mathrm{~min}^{-1}$ at $t=20^{\circ} \mathrm{C}$ and $p=1013 \mathrm{hPa}$. Flow checks with a Gilibrator flow meter showed that the flow was $4.7 \pm 0.2 \mathrm{~L} \mathrm{~min}^{-1}$ at the same conditions. Concentrations were converted to STP conditions, taking the flow calibrations into account. The filter spots were set to change when the maximum attenuation (ATN) exceeded 125 . The average and standard deviation of the last ATN values before filter spot changes were $127 \pm 3,99 \pm 6$, $87 \pm 7,79 \pm 7,73 \pm 8,54 \pm 7$, and $49 \pm 7$ for $\lambda=370,470$, $520,590,660,880$, and $950 \mathrm{~nm}$, respectively. These are given here to be used for evaluating the effect of the correction function.

\subsection{Calculation of the compensation parameter}

The core of the present paper is to analyze factors affecting the compensation parameter $k$ that is used to correct $\mathrm{BC}$ mass concentrations in

$\mathrm{BC}_{\text {corr }}=(1+k \cdot \mathrm{ATN}) \mathrm{BC}_{0}$, where $\mathrm{BC}_{0}$ is the original non-corrected $\mathrm{BC}$ mass concentration and ATN is the attenuation reported by the aethalometer. The $k$ of filter spot $i$ was calculated from

$k=\frac{1}{\operatorname{ATN}_{i, \text { last }}}\left(\frac{\mathrm{BC}_{0, i+1, \text { first }}}{\mathrm{BC}_{0, i, \text { last }}}-1\right)$,

where $\operatorname{ATN}_{i, \text { last }}$ is the last attenuation of filter spot $i$ before the filter spot change, $\mathrm{BC}_{0, i, \text { last }}$ and $\mathrm{BC}_{0, i+1}$,first are the original non-corrected $\mathrm{BC}$ mass concentrations of the last measurement point of filter spot $i$ and the first measurement point of spot $i+1$, respectively. In practice the averages of the three last measurement points of filter spot $i$ and the averages of the three first measurements of filter spot $i+1$ were used, as in the original paper (Virkkula et al., 2007). At this point it is worth noting the analogy of the $k$ factor in Eq. (1) and that of $\mathrm{BC}_{\text {corr }}=\mathrm{BC}_{0} /(1-k \cdot \mathrm{ATN})$, which is used in the dual-spot aethalometer, model AE33 (Drinovec et al., 2015). 1/(1-kATN) is the sum of a geometric series $1+k \mathrm{ATN}+(k \mathrm{ATN})^{2}+\ldots$ Typically published values of $k$ are less than 0.01 and aethalometers are usually changing spots when ATN is less than 100 , so the terms $(k \mathrm{ATN})^{n}$ with $n>1$ are small and $1 /(1-k \mathrm{ATN}) \approx 1+k \mathrm{ATN}$. This suggests that the results to be shown below are qualitatively valid also for the new model.

\subsection{Calculation of absorption coefficients}

The aethalometer data were first used to calculate the uncorrected attenuation coefficients, here $\sigma_{0}$, by multiplying the original non-corrected $\mathrm{BC}$ mass concentration $\left(\mathrm{BC}_{0}\right.$ above $)$ given by the aethalometer with the wavelength-dependent BC mass attenuation coefficient used by the instrument's software. Note that in several papers the symbol $b_{\text {ATN }}$ has been used for the attenuation coefficient. In the present paper the symbol $b$ is reserved for backscatter fraction, however, and the subscript of $\sigma_{0}$ is there to show that it was calculated from $\mathrm{BC}_{0}$. To calculate the absorption coefficients $\left(\sigma_{\mathrm{a} p}\right)$, several algorithms have been presented that in principle can be expressed in the form of

$\sigma_{\mathrm{a} p}=\frac{f \sigma_{0}-s \sigma_{\mathrm{s} p}}{C_{\mathrm{ref}}}$,

where $f$ is a loading correction function, $\mathrm{s}$ is a fraction of the light scattering coefficient $\sigma_{\mathrm{s} p}$ that causes reduction of light transmittance and would be interpreted as absorption (= apparent absorption) if not taken into account, and $C_{\text {ref }}$ the multiple scattering correction factor. Note, however, that $\mathrm{s}$ is not any constant factor but also a wavelength-dependent function. For instance, if the algorithm of Arnott et al. (2005) is arranged as in Eq. (3), it is obvious that s depends on the absorption coefficient accumulated since the change of the filter spot and, if the algorithm by Collaud Coen et al. (2010) is arranged as in Eq. (3), it can be seen that $\mathrm{s}$ is a function of the attenuation at any given time step, among other things. 


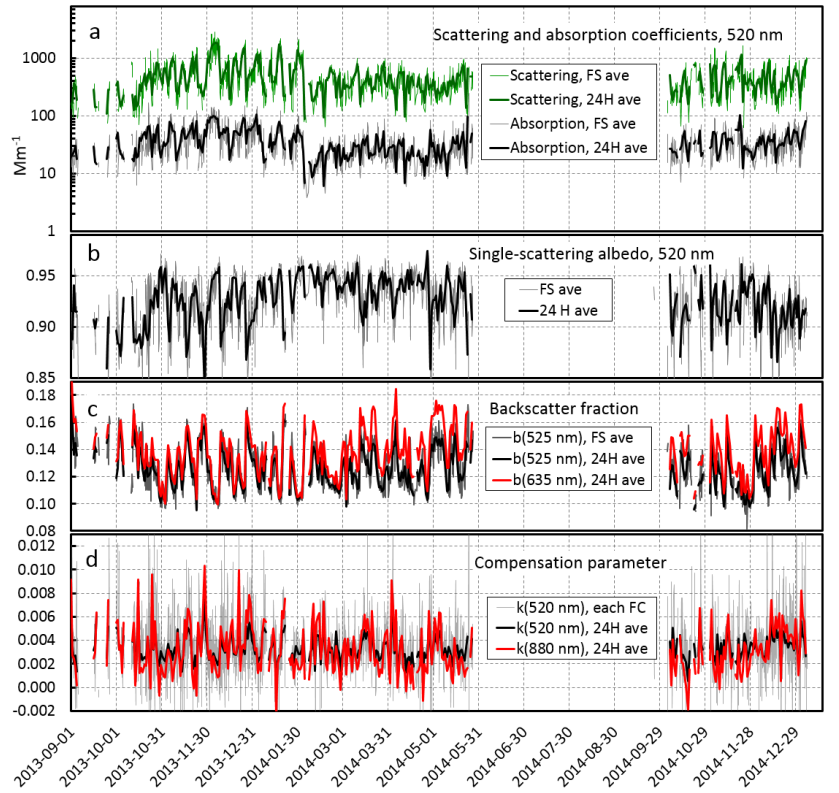

Figure 1. Overview of the data. (a) Scattering and absorption coefficients at $\lambda=520 \mathrm{~nm}$, (b) single-scattering albedo at $\lambda=520 \mathrm{~nm}$, (c) backscatter fraction at $\lambda=525 \mathrm{~nm}$ and $\lambda=635 \mathrm{~nm}$, and (d) the compensation parameter $(k)$ at $\lambda=520 \mathrm{~nm}$ and at $\lambda=880 \mathrm{~nm}$. In (a-c) the thin lines show the filter-spot-averaged (FS ave) values and in (d) the individual compensation parameters at each filter change (FC). The thick lines show the $24 \mathrm{~h}$-averaged values in all figures.

In the present work the absorption coefficients were calculated according to both the Arnott et al. (2005) and Collaud Coen et al. (2010) algorithms with the respective mean $C_{\text {ref }}$ values of 4.12 and 4.26 obtained for the Cabauw station by Collaud Coen et al. (2010). The differences of the absorption coefficients calculated from these two algorithms were small and all the conclusions to be presented below were the same. Therefore, even though both algorithms were used, most of the absorption coefficients presented in the figures below were calculated with the formula by Collaud Coen et al. (2010). The average $C_{\text {ref }}$ for Cabauw was chosen from Table 4 of Collaud Coen et al. (2010), which presents the $C_{\text {ref }}$ averages for four stations: Jungfraujoch, Cabauw, Mace Head, and Hohenpeissenberg. Jungfraujoch is a clean, high Alpine site far from emission sources, Hohenpeissenberg a rural mountain site in southern Germany with clean air (e.g., Putaud et al., 2010), and Mace Head a clean marine site on the Irish west coast. Cabauw is in the Netherlands in a region near populated and industrialized areas (e.g., Collaud Coen et al., 2010). Therefore, of these four sites the aerosol in Cabauw can be assumed to be most similar to that observed at the SORPES station in Nanjing. A similar value $C_{\text {ref }}=4.22$ was also obtained by Segura et al. (2014) for a continental station in Spain.

There is a large uncertainty in the $C_{\text {ref }}$ even at one station: for example, in Cabauw the seasonal averages varied from less than 3 to close to 5 (Collaud Coen et al., 2010), which leads to large uncertainties of both $\sigma_{\mathrm{a} p}$ and the singlescattering albedo $\left(\omega_{0}=\sigma_{\mathrm{s} p} /\left(\sigma_{\mathrm{s} p}+\sigma_{\mathrm{a} p}\right)\right)$. It is obvious from Eq. (3) that the relative uncertainty of $C_{\text {ref }}$ is also the relative uncertainty of $\sigma_{\mathrm{a} p}$. However, one of the goals of the present work is to study the variations of the compensation parameter as a function of the variations of $\omega_{0}$ so the absolute $\omega_{0}$ values are not that important in this work.

\subsection{Averaging}

The hypothesis here is that all particles sampled on the filter prior to the spot change affect the $k$ factor. Therefore all scattering and absorption coefficients, single-scattering albedos and backscatter fractions were averaged for each aethalometer filter spot sampling period. No conventional hourly averages are presented.

Also, the daily or $24 \mathrm{~h}$ averages are non-conventional: they were calculated by averaging the compensation parameters and the corresponding filter-spot-averaged scattering and absorption coefficients that were calculated from the aethalometer filter spot changes during any given day. The number of filter changes to be used for the averaging varied according to the concentration level: during low concentrations there may have been only one or two filter spot changes, during high concentrations more. Below, in the analyses of daily averages, only those days have been used during which at least two filter spot changes occurred. During the analyzed period, the average, the median, and the maximum number of filter spot changes were $6.4,6$, and 18 during one day, respectively.

\section{Results and discussion}

\subsection{Overview of the data}

Figure 1 shows filterspot-averaged and $24 \mathrm{~h}$-averaged data that fulfilled the criteria for further analyses: the relative humidity in the nephelometer sample volume had to be less than $50 \%$, both the nephelometer and the aethalometer data had to be continuous for at least $24 \mathrm{~h}$. This ruled out summer months (June-August) and most of September. There were 2066 filter spot changes and 342 days that were used for further analyses. In the accepted data the average \pm standard deviation and median of the RH in the nephelometer sample volume were $18 \pm 8 \%$ and $16 \%$, respectively.

Some descriptive statistics of the optical data are given here, even though a more detailed analysis will be presented by Shen et al. (2015). The average \pm standard deviation of daily averaged $\sigma_{\mathrm{s} p}, \sigma_{\mathrm{a} p}$, and $\omega_{0}$ data at $\lambda=520 \mathrm{~nm}$ were $495 \pm 260 \mathrm{Mm}^{-1}, 37 \pm 19 \mathrm{Mm}^{-1}$, and $0.92 \pm 0.02$, respectively. The 5th to 95th percentile ranges of the cumulative distributions of the daily averaged $\sigma_{\mathrm{s} p}, \sigma_{\mathrm{a} p}$, and $\omega_{0}$ at $\lambda=520 \mathrm{~nm}$ were $167-1117 \mathrm{Mm}^{-1}, 14-79 \mathrm{Mm}^{-1}$, and $0.88-$ 0.95 , respectively. 


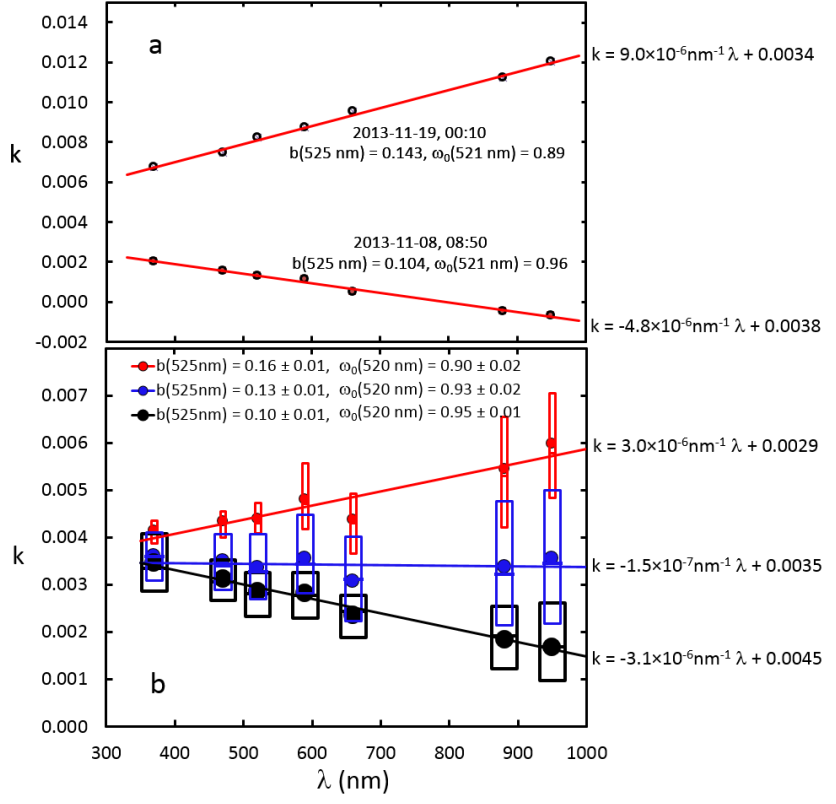

Figure 2. Wavelength dependency of the $k$ factor (a) on 8 and 19 November 2013 and (b) in the whole data after classification into three bins of the green backscatter fraction. In (b) the box plots present the 25 th to 75 th percentiles, the middle lines the medians and the circles the averages in each bin. In (a) the lines represent linear regression fittings to the individual $k$ factors and in (b) linear regression fittings to the average $k$ in each wavelength and backscatter bin.

There were many several-day-long pollution episodes in November 2013-January 2014 and again the following autumn in November 2014 during which scattering and absorption coefficients exceeded 1000 and $100 \mathrm{Mm}^{-1}$, respectively. The cycling of pollution episodes and cleaner days was also associated with simultaneous cycling of $\omega_{0}$ and the backscatter fraction $b$. The slow variations were due to changes in meteorological conditions and transport routes of air masses. Further analysis of them is out of the scope of the present paper, however.

\subsection{Wavelength dependency of the compensation parameter}

The compensation parameters (Fig. 1d) calculated for each individual filter-spot change were noisy; for instance, for $\lambda=520 \mathrm{~nm} k$ varied from negative to larger than 0.01 and at first sight there are only weak common features with the other time series. The noise of $k$ is due to fast real concentration variations: for instance, if the true BC mass concentration is clearly higher just before the filter spot change, $k$ becomes negative. It was therefore stated already in the original paper by Virkkula et al. (2007) that during variable concentrations the use of average $k$ may lead to a more reasonable correction than the individual $k$ values. In the present work, the daily averaged compensation parameters present similarities with the time series of $\omega_{0}$ and b: in particular, when the backscatter fraction $b$ is high, the compensation parameters seem higher than when $b$ is low. The compensation parameter time series (Fig. 1d) also shows that sometimes the green $k(\lambda=520 \mathrm{~nm})$ was larger than the near-infrared $k$ $(\lambda=880 \mathrm{~nm})$ and vice versa.

These observations were used and two filter spot changes were picked up during which the filter-spot-averaged $b$ were clearly different from each other: on 8 and 19 November 2013 when the backscatter fraction at $\lambda=525 \mathrm{~nm}$ was 0.104 and 0.143 , respectively (Fig. 2a). Note that during the first filter spot change $\omega_{0}$ was clearly higher than during the second one. Also, the compensation parameters calculated for the seven wavelengths of the aethalometer were very different for these two spot changes: during the first one they were much lower than during the second one, and during the first one they decreased with wavelength and during the second one they increased with wavelength. Linear regression was applied to this close to linear dependency (Fig. 2a). A line

$k=a_{k} \lambda+k_{0}$

was fit through the $7 k$ values obtained for each filter spot change of the whole data set. Only the slope $a_{k}$ is of interest here. Its interpretation is simple: when $a_{k}>0$ the compensation parameters increase with wavelength, when $a_{k}<0$, the compensation parameters decrease with wavelength. As noted already earlier, the compensation parameters obtained for individual spot changes are noisy. Therefore, more relevant information was obtained when the compensation parameters from all spot changes were classified according to the associated filter-spot-averaged backscatter fraction of green light and simple descriptive statistics were calculated. Figure $2 \mathrm{~b}$ shows the averages, medians and the 25 th to 75 th percentile ranges of the cumulative distributions of the compensation parameters at three different backscatter fraction ranges. The lines shown in the figure were fit to the average compensation parameters in each wavelength and bin of $b$. Note again that $\omega_{0}$ was high when $b$ was low and low when $b$ was high and $a_{k}$ increased with increasing $b$.

Another interesting observation can be made about Fig. 2: the range of compensation parameters is larger the longer the wavelength is. This suggests that the longer wavelengths are more sensitive to the factors affecting the compensation. The near-infrared wavelength at $\lambda=880 \mathrm{~nm}$ is the one that is used in most aethalometers, even single-wavelength ones, and therefore more attention will be paid to it than to the longest wavelength $(\lambda=950 \mathrm{~nm})$.

A shorter, 2-month time series of the data is presented in Fig. 3. In addition to those quantities presented in Fig. 1 also the slope $a_{k}$ calculated for each filter spot change and the respective daily averages are shown (Fig. 3d). There are some interesting features in the time series of $\sigma_{\mathrm{s} p}, \sigma_{\mathrm{a} p}, \omega_{0}$, and $b$. First, the most polluted episodes, for instance on 4-8 December, were associated with the highest $\sigma_{\mathrm{s} p}$ and the highest $\omega_{0}$, suggesting that the contribution of light-absorbing material, 


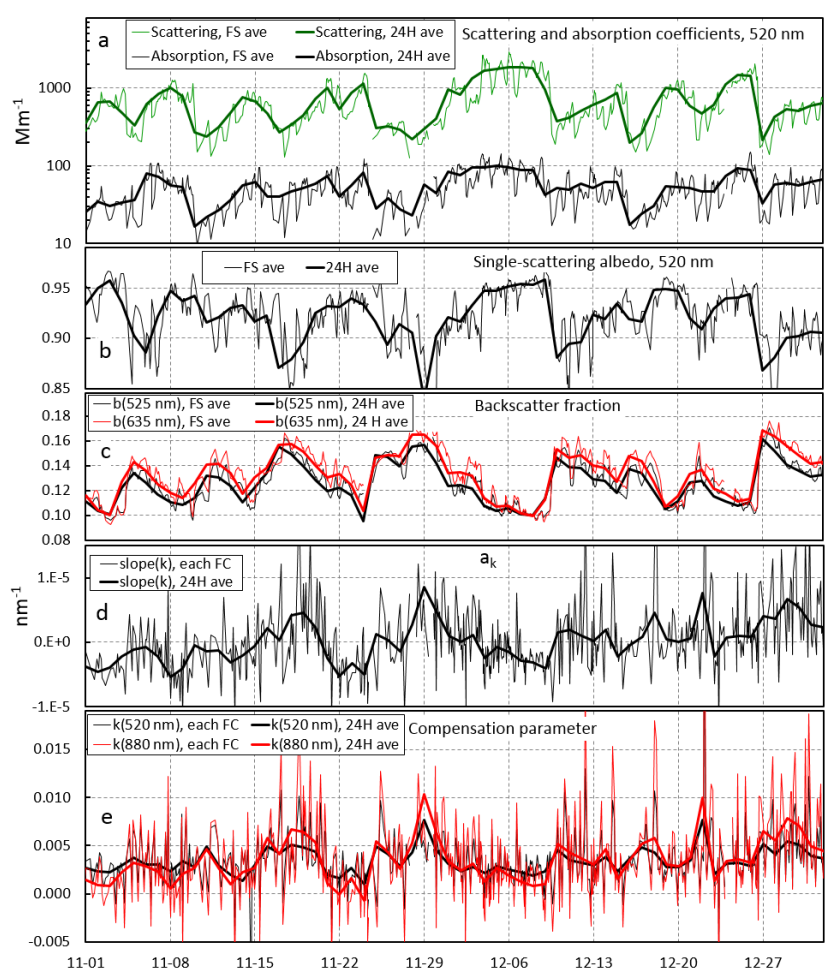

Figure 3. Selected optical properties in November-December 2013. (a) Scattering and absorption coefficients at $\lambda=520 \mathrm{~nm}$, (b) single-scattering albedo at $\lambda=520 \mathrm{~nm}$, (c) backscatter fraction at $\lambda=525 \mathrm{~nm}$ and $\lambda=635 \mathrm{~nm}$, (d) the slope $\left(a_{k}\right)$ of the wavelength dependency of the compensation parameter, and (e) the compensation parameter $(k)$ at $\lambda=520 \mathrm{~nm}$ and at $\lambda=880 \mathrm{~nm}$. In $(\mathbf{a}-\mathbf{c})$ the thin lines show the filter-spot-averaged (FS ave) values, in (d-e) the individual slopes and compensation parameters at each filter change (FC). The thick lines show the $24 \mathrm{~h}$-averaged values in all figures.
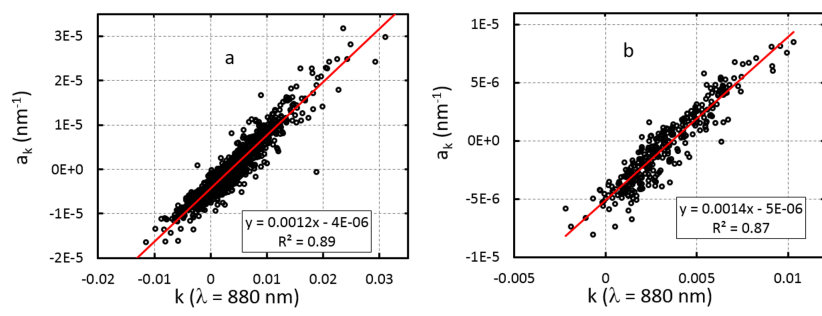

Figure 4. The slope of the wavelength dependency of the compensation parameter $\left(a_{k}\right)$ as a function of the compensation parameter $k$ at $\lambda=880 \mathrm{~nm}$ in (a) each filter spot change, (b) $24 \mathrm{~h}$ averages.

mainly $\mathrm{BC}$, to the aerosol mass in the highly polluted air was clearly lower than during the less-polluted periods, and that the polluted aerosol consisted of some light-scattering material, for instance of secondary inorganic or organic compounds. The other observation is that during the highest pollution episodes the backscatter fraction was lower, which suggests that the particles were then bigger than during the less-polluted periods (Fig. 3c). Still another noteworthy ob-
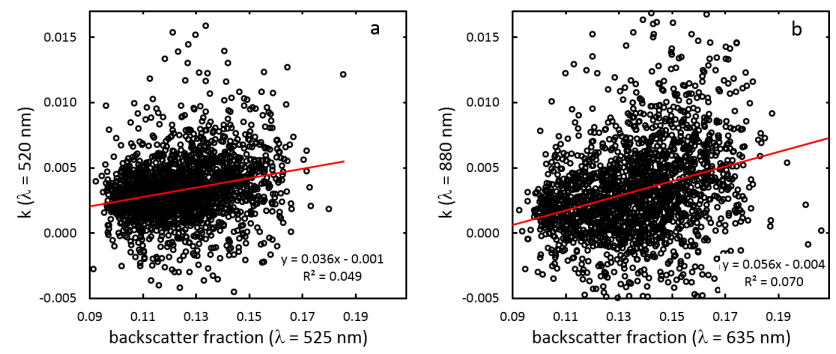

Figure 5. The compensation parameter $(k)$ of individual filter spot changes calculated for (a) green $(\lambda=520 \mathrm{~nm})$ and (b) near-infrared $(\lambda=880 \mathrm{~nm})$ light as a function of filter-spot-averaged backscatter fraction at the nearest nephelometer wavelengths $\lambda=525 \mathrm{~nm}$ and $\lambda=635 \mathrm{~nm}$.

servation concerning these four parameters is that there are clear diurnal cycles. To mention one, the diurnal cycle of $\omega_{0}$ is such that the highest values were reached at daytime and the lowest at night, which could be explained so that $\mathrm{BC}$ particles get coated during the course of the day by condensation of some scattering material. However, more detailed analyses of the pollution episodes and the chemical composition are out of the scope of the present paper.

As far as the compensation parameters $(k)$ and their wavelength dependency $\left(a_{k}\right)$ are concerned, their time series (Fig. 3d and e) reveal features that have similarities with those of the other presented quantities. These are that both $k$ and $a_{k}$ increase and decrease roughly at the same time as $b$ and the opposite way compared with $\omega_{0}$. The time series in Fig. 3d and e also show that $a_{k}$ obviously increases and decreases simultaneously with $k$, which means that they are not really independent. The scatter plots of both individual and daily averaged $a_{k}$ vs. $k$ at $\lambda=880 \mathrm{~nm}$ (Fig. 4) show that $a_{k}$ is linearly dependent on the compensation parameter. This means that when $k$ is known at one wavelength, it is possible to estimate it at other wavelengths also. The linear fittings in the scatter plots cross the zero line of $a_{k}$ when $k(\lambda=880 \mathrm{~nm})=0.0036 \pm 0.0022$, which means that then all compensation parameters were roughly equal at all wavelengths and when $k(\lambda=880 \mathrm{~nm})$ was larger than this $k$ increased with wavelength and vice versa. The above uncertainty of the zero-line crossing was calculated from the uncertainties of the slope and offset of the linear regressions.

\subsection{Effect of backscatter fraction}

Since the time series of $k$ and $b$ have similarities, it is logical to calculate their linear regressions. The correlation coefficient of $k$ calculated for each filter change with filter-spot averaged $b$ is low (Fig. 5). This is due to the high uncertainty of the individual compensation parameters, for reasons discussed already above. There is a positive correlation, however, and it is demonstrated visually by classifying the daily averaged compensation parameters at four wavelengths 
Table 1. Regression statistics $\left(y=\beta_{1} x+\beta_{0}\right)$ of compensation parameter vs. backscatter fraction. SE: standard error of $\beta_{1}$; $95 \%$ confidence range of $\beta_{1}$; d.f.: degrees of freedom; $t=\beta_{1}$ /SE; $p$ : $p$ value of the Student's $t$ distribution.

\begin{tabular}{ccccccccc}
\hline \multicolumn{1}{c}{ Calculated by using each filter change } \\
$x$ & $y$ & $r$ & $\beta_{1}$ & SE & $95 \%$ confidence range & d.f. & $t$ & $p$ \\
\hline$b(450)$ & $k(470)$ & 0.18 & 0.024 & 0.003 & $(0.018-0.030)$ & 2048 & 8.2 & $5.6 \times 10^{-16}$ \\
$b(525)$ & $k(520)$ & 0.22 & 0.036 & 0.004 & $(0.029-0.043)$ & 2048 & 10.3 & $2.9 \times 10^{-24}$ \\
$b(635)$ & $k(660)$ & 0.21 & 0.032 & 0.003 & $(0.026-0.039)$ & 2048 & 9.5 & $5.7 \times 10^{-21}$ \\
$b(635)$ & $k(880)$ & 0.26 & 0.056 & 0.005 & $(0.047-0.065)$ & 2048 & 12.4 & $4.3 \times 10^{-34}$ \\
\hline \multicolumn{8}{c}{ Calculated by using all daily averages } \\
$x$ & $y$ & $r$ & $\beta_{1}$ & SE & $95 \%$ confidence range & d.f. & $t$ & $p$ \\
\hline$b(450)$ & $k(470)$ & 0.28 & 0.017 & 0.003 & $(0.011-0.024)$ & 320 & 5.2 & $3.0 \times 10^{-07}$ \\
$b(525)$ & $k(520)$ & 0.38 & 0.029 & 0.004 & $(0.021-0.037)$ & 320 & 7.3 & $2.3 \times 10^{-12}$ \\
$b(635)$ & $k(660)$ & 0.32 & 0.025 & 0.004 & $(0.017-0.033)$ & 320 & 6. & $6.5 \times 10^{-09}$ \\
$b(635)$ & $k(880)$ & 0.43 & 0.048 & 0.006 & $(0.037-0.060)$ & 320 & 8.4 & $1.3 \times 10^{-15}$ \\
\hline
\end{tabular}
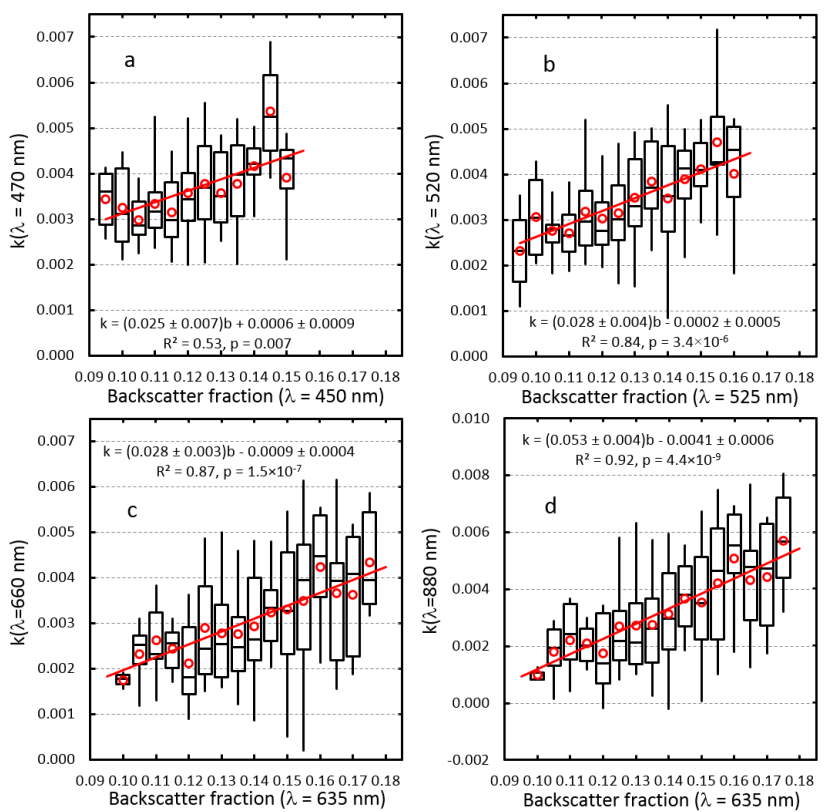

Backscatter fraction $(\lambda=635 \mathrm{~nm})$

Figure 6. Daily averaged compensation parameters of (a) blue $(\lambda=470 \mathrm{~nm})$, (b) green $(\lambda=520 \mathrm{~nm})$, (c) red $(\lambda=660 \mathrm{~nm})$, and (d) near-infrared $(\lambda=880 \mathrm{~nm})$ light classified into 0.005 wide bins of the backscatter fraction at the nearest nephelometer wavelengths $(\lambda=450,525$, and $635 \mathrm{~nm})$. The box plots present the 5th, 25th, 50th, 75th, and 95th percentiles and the circles the averages in each bin. The lines are linear fittings to the bin averages and the uncertainties of the slope and offset the standard errors obtained from the fitting.

( $\lambda=470,520,660$, and $880 \mathrm{~nm})$ into bins of backscatter fractions at the nearest nephelometer wavelengths $(\lambda=450,525$, and $635 \mathrm{~nm}$ ) (Fig. 6). The width of the backscatter fraction bins was 0.005 . The averages, 5 th, 25 th, 50th, 75 th, and 95 th percentiles of the cumulative distribution of the compensation parameters in each bin were calculated.
The compensation parameter medians and averages correlated positively with the backscatter fractions, and so did the other percentiles, but their correlation was weaker. Note that the slopes of the linear regressions of $k$ vs. $b$ are almost the same when the wavelength of both $k$ and $b$ are approximately the same (Fig. $6 \mathrm{a}-\mathrm{c}$ ). When $k$ at $\lambda=880 \mathrm{~nm}$ is plotted against $b$ at $\lambda=635 \mathrm{~nm}$, the slope is almost twice as high.

Instead of paying much attention to the $R^{2}$ values, it is more relevant to test the statistical significance of the slope of the regression of compensation parameter vs. backscatter fraction, i.e., $\beta_{1}$ in $k=\beta_{1} b+\beta_{0}$. The null hypothesis that the slope is not dependent on the b; i.e., $\beta_{1}=0$ was tested using test statistics given by the estimate of the slope divided by its standard error $\left(t=\beta_{1} / \mathrm{SE}\right)$. The test statistics were compared with the Student's $t$ distribution on $n-2$ (sample size - number of regression coefficients) degrees of freedom. The regressions were calculated both for each individual filter change and for daily averages. Four compensation parameter-backscatter fraction pairs were used: blue: $k(\lambda=470 \mathrm{~nm})$ vs. $b(\lambda=450 \mathrm{~nm})$, green: $k(\lambda=520 \mathrm{~nm})$ vs. $b(\lambda=525 \mathrm{~nm})$, red $k(\lambda=660 \mathrm{~nm})$ vs. $b(\lambda=635 \mathrm{~nm})$, and red-near-infrared: $k(\lambda=880 \mathrm{~nm})$ vs. $b(\lambda=635 \mathrm{~nm})$. The last combination differs from the other three in that the wavelength of $k$ and $b$ are not close to the same like in the other cases. The reason this is considered to be relevant here is that most aethalometers have the $880 \mathrm{~nm}$ wavelength and in most three-wavelength nephelometers the longest wavelength is $600-700 \mathrm{~nm}$. The results are presented in Table 1. The $p$ values for all wavelengths are all low $(<0.001)$, which gives strong evidence against the null hypothesis, indicating that the slope is not 0 and that there is a linear relationship between $k$ and $b$.

No detailed theoretical explanation of this relationship is attempted to be given here, only some qualitative discussion. The aethalometer functions in a way similar to the PSAP. Müller et al. (2014) showed that the optical depth of an aerosol-loaded PSAP filter is a function of the asymmetry parameter $g_{\mathrm{p}}$ of particles. $g_{\mathrm{p}}$ increases with decreasing 


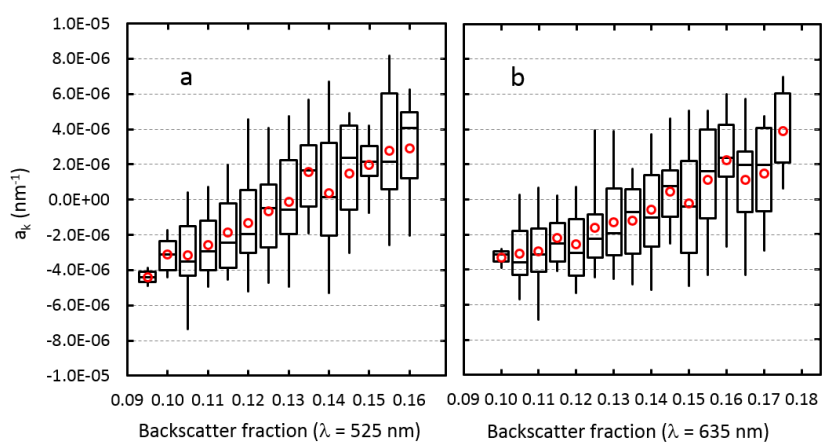

Figure 7. Daily averaged slope $\left(a_{k}\right)$ of the compensation parameter classified into 0.005 wide bins of the backscatter fraction of (a) green $(\lambda=525 \mathrm{~nm})$ and $(\mathrm{b})$ red $(\lambda=635 \mathrm{~nm})$ light. The box plots present the 5th, 25th, 50th, 75th, and 95th percentiles and the circles the averages in each bin.

backscatter fraction; see, e.g., the parameterization by Andrews et al. (2006). Müller et al. (2014) showed that for a constant scattering optical depth the optical depth of an aerosol-loaded filter was the higher the smaller the $g_{\mathrm{p}}$ of the aerosol was or in other words, the higher the backscatter fraction was. This means that when purely scattering aerosol is collected on an aethalometer filter, the optical depth is the larger the larger $b$ is. This should further mean larger apparent absorption coefficients and thus higher BC mass concentrations with larger $b$. This is also consistent with published measurements made with the new AE 33: Drinovec et al. (2015) reported that the apparent absorption due to small ammonium sulfate particles was clearly larger than that due to large particles. Consequently, the $\sigma_{\mathrm{a} p}$ and $\mathrm{BC}$ should be corrected downwards, i.e., the compensation parameter $k$ should be $<0$ and the more negative the larger the backscatter fraction is. However, for the real atmospheric aerosol the opposite was here observed: the compensation parameter was the larger the larger backscatter fraction was (Fig. 6). This means that the non-corrected absorption coefficients and $\mathrm{BC}$ mass concentrations were underestimated the more the higher $b$ was. Here the qualitative explanation is the counteracting concept of shadowing, presented by Weingartner et al. (2003): due to enhanced scattering the absorbing particles absorb a higher fraction of light and effectively reduce the optical path. This leads to an underestimation of the true $\sigma_{\mathrm{a} p}$ and $\mathrm{BC}$ and therefore the compensation parameter should be positive.

Also, $a_{k}$, the wavelength dependency of the compensation parameter depends on the backscatter fraction. Especially the relationship between $a_{k}$ and $b$ of green light is strikingly linear (Fig. 7). At $b(\lambda=525 \mathrm{~nm}) \approx 0.13, a_{k} \approx 0$, for smaller backscatter fractions $a_{k}<0$ and for larger backscatter fractions $a_{k}>0$. No detailed explanation can be given at this point but qualitatively the above relationship means that for small particles the correction is the larger the larger the wavelength is and for large particles the other way around.

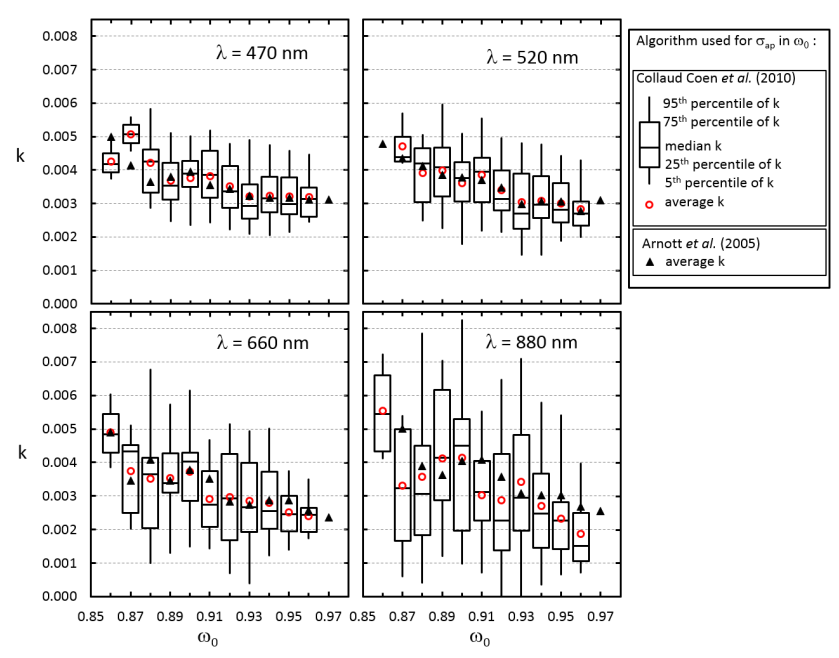

Figure 8. Daily averaged compensation parameters of blue $(\lambda=470 \mathrm{~nm})$, green $(\lambda=520 \mathrm{~nm})$, red $(\lambda=660 \mathrm{~nm})$, and nearinfrared $(\lambda=880 \mathrm{~nm})$ light classified into 0.01 wide bins of the single-scattering albedo $\left(\omega_{0}\right)$ at the same wavelengths. The box plots present the 5 th, 25 th, 50th, 75th, and 95th percentiles and the circles the averages in each bin. Most $\omega_{0}$ bins are based on $\sigma_{\mathrm{a}} p$ calculated with the Collaud Coen et al. (2010) algorithm; the black triangles are the averages of compensation parameters classified into $\omega_{0}$ bins with the $\sigma_{\mathrm{a} p}$ calculated by using the Arnott et al. (2005) algorithm.

\subsection{Effect of single-scattering albedo}

The relationship of the single-scattering albedo and the compensation parameter was analyzed analogically. The $k$ s were classified into bins of $\omega_{0}$ at four aethalometer wavelengths $(\lambda=470,520,660$, and $880 \mathrm{~nm})$. The width of the $\omega_{0}$ bins was 0.01 . The averages, 5 th, 25 th, 50 th, 75 th, and 95 th percentiles of the cumulative distribution of the compensation parameters were calculated. The bin averages and medians decreased almost monotonically with increasing $\omega_{0}$, but the ranges were large (Fig. 8). Note that in Fig. 8 the $k$ vs. $\omega_{0}$ relationship of the bin averages is plotted both by using the Collaud Coen et al. (2010) algorithm and the Arnott et al. (2005) algorithm simply to show that the main relationship, decreasing $k$ with increasing $\omega_{0}$, did not depend on the algorithm used for calculating absorption coefficients $\sigma_{\mathrm{a} p}$. It is worth noting at this point that the absolute values of $\sigma_{\mathrm{a} p}$ and $\omega_{0}$ are very uncertain because of the uncertainty of the multiple scattering correction factor $C_{\text {ref }}$. The $\omega_{0}$ values shown in Fig. 8 were calculated with $C_{\text {ref values of } 4.12 \text { and }}$ 4.26 as explained above but if $C_{\text {ref }}$ is smaller $\omega_{0}$ is lower than that shown in Fig. 8. This would not change the main result: $k$ decreases with increasing $\omega_{0}$. The decrease is also statistically significant. Linear regression of $k$ vs. $\omega_{0}$ was calculated both for individual filter changes and for daily averages, as above for $k$ vs. $b$. The statistics are presented in Table 2. The $p$ values are somewhat higher than in Table 1 but still low 
Table 2. Regression statistics $\left(y=\beta_{1} x+\beta_{0}\right)$ of compensation parameter vs. single-scattering albedo. Detailed column description as in Table 1 .

\begin{tabular}{ccccccccc}
\hline \multicolumn{1}{c}{ Calculated by using each filter change } \\
$x$ & $y$ & $r$ & $\beta_{1}$ & SE & $95 \%$ confidence range & d.f. & $t$ & $p$ \\
\hline$\omega_{0}(470)$ & $k(470)$ & 0.07 & -0.006 & 0.002 & $(-0.009--0.002)$ & 2048 & -3.4 & $7.3 \times 10^{-04}$ \\
$\omega_{0}(520)$ & $k(520)$ & 0.08 & -0.008 & 0.002 & $(-0.012--0.004)$ & 2048 & -3.8 & $1.3 \times 10^{-04}$ \\
$\omega_{0}(660)$ & $k(660)$ & 0.07 & -0.007 & 0.002 & $(-0.012--0.003)$ & 2048 & -3.1 & $2.0 \times 10^{-03}$ \\
$\omega_{0}(880)$ & $k(880)$ & 0.08 & -0.010 & 0.003 & $(-0.016--0.004)$ & 2048 & -3.5 & $4.7 \times 10^{-04}$ \\
\hline
\end{tabular}

Calculated by using all daily averages

\begin{tabular}{ccccccccc}
$x$ & $y$ & $r$ & $\beta_{1}$ & SE & $95 \%$ confidence range & d.f. & $t$ & $p$ \\
\hline$\omega_{0}(470)$ & $k(470)$ & 0.27 & -0.011 & 0.002 & $(-0.016--0.007)$ & 320 & -5.1 & $5.9 \times 10^{-07}$ \\
$\omega_{0}(520)$ & $k(520)$ & 0.31 & -0.015 & 0.003 & $(-0.020-0.010)$ & 320 & -5.9 & $9.6 \times 10^{-09}$ \\
$\omega_{0}(660)$ & $k(660)$ & 0.26 & -0.015 & 0.003 & $(-0.021--0.009)$ & 320 & -4.8 & $2.0 \times 10^{-06}$ \\
$\omega_{0}(880)$ & $k(880)$ & 0.25 & -0.019 & 0.004 & $(-0.027--0.011)$ & 320 & -4.5 & $8.1 \times 10^{-06}$ \\
\hline
\end{tabular}

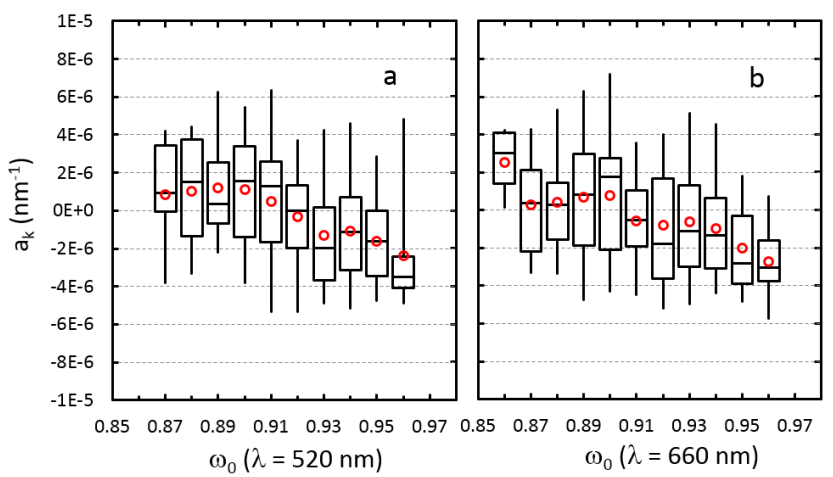

Figure 9. Daily averaged slope $\left(a_{k}\right)$ of the compensation parameter classified into 0.01 wide bins of the single-scattering albedo $\left(\omega_{0}\right)$ at (a) green $(\lambda=520 \mathrm{~nm})$ and (b) red $(\lambda=660 \mathrm{~nm})$ wavelengths. The box plots present the 5 th, 25 th, 50 th, 75 th, and 95 th percentiles and the circles the averages in each bin.

enough to conclude that the relationship is statistically significant.

A simple theoretical explanation for the decreasing $k$ with increasing $\omega_{0}$ can be given. If it is assumed that (1) the loading correction function $f$ in Eq. (3) equals $1+k$ ATN and (2) that the dependence on the scattering coefficient is incorporated into the compensation parameter, the equation for the absorption coefficient becomes

$\sigma_{\mathrm{a} p}=\frac{1+k \mathrm{ATN}}{C_{\mathrm{ref}}} \sigma_{0}$.

On the other hand, if it is assumed that the absorption coefficient is calculated from Eq. (3) where $f$ is not the same function as in Eq. (5) and where the dependence on the scattering coefficient is explicitly presented and if the two Eqs. (3) and (5) are set equal the compensation parameter can be solved as

$$
\begin{aligned}
& \frac{1+k \mathrm{ATN}}{C_{\mathrm{ref}}} \sigma_{0}=\frac{f \sigma_{0}-s \sigma_{\mathrm{s} p}}{C_{\mathrm{ref}}} \\
& \Leftrightarrow k=\frac{1}{\mathrm{ATN}}\left(f-1-\frac{s \sigma_{\mathrm{s} p}}{\sigma_{0}}\right) .
\end{aligned}
$$

When Eq. (3) is again rearranged as $\sigma_{0}=\left(C_{\mathrm{ref}} \sigma_{\mathrm{a} p}+\right.$ $\left.s \sigma_{\mathrm{s} p}\right) / f$ and inserted in Eq. (6), the compensation parameter can be expressed as

$$
\begin{aligned}
k & =\frac{1}{\operatorname{ATN}}\left(f-1-\frac{s \sigma_{\mathrm{s} p}}{\frac{C_{\mathrm{ref}} \sigma_{\mathrm{a} p}+s \sigma_{\mathrm{s} p}}{f}}\right) \\
& =\frac{1}{\operatorname{ATN}}\left(f\left(1-\frac{\sigma_{\mathrm{s} p}}{\frac{C_{\mathrm{ref}}}{s} \sigma_{\mathrm{a} p}+\sigma_{\mathrm{s} p}}\right)-1\right) .
\end{aligned}
$$

The term $\sigma_{\mathrm{s} p} /\left(\frac{C_{\text {ref }}}{s} \sigma_{\mathrm{a} p}+\sigma_{\mathrm{s} p}\right)$ is not exactly identical to the single-scattering albedo $\omega_{0}$, but it also approaches unity when $\omega_{0}$ approaches unity and $f\left(1-\sigma_{\mathrm{s} p} /\left(\frac{C_{\mathrm{ref}}}{s} \sigma_{\mathrm{a} p}+\sigma_{\mathrm{s} p}\right)\right) \rightarrow$ 0 , and then $k$ may even become negative. In other words, the compensation parameter can be negative but the resulting absorption coefficient can never be negative; this sets the limit to it.

The relationship between $a_{k}$ and the single-scattering albedo is very similar to that between $k$ and $\omega_{0}$ : also, $a_{k}$ decreases with increasing $\omega_{0}$ (Fig. 9). In other words for darker aerosols, $\omega_{0}$ less than approximately 0.92 , the correction increases with wavelength and at higher $\omega_{0}$ it decreases with wavelength. No theoretical explanation could be given at this point.

\subsection{Separating the effects of single-scattering albedo and backscatter fraction}

The above analysis showed that the compensation parameter depends both on the single-scattering albedo and the backscatter fraction. Which of them is a more dominant factor? It is very difficult if not impossible to show from the 

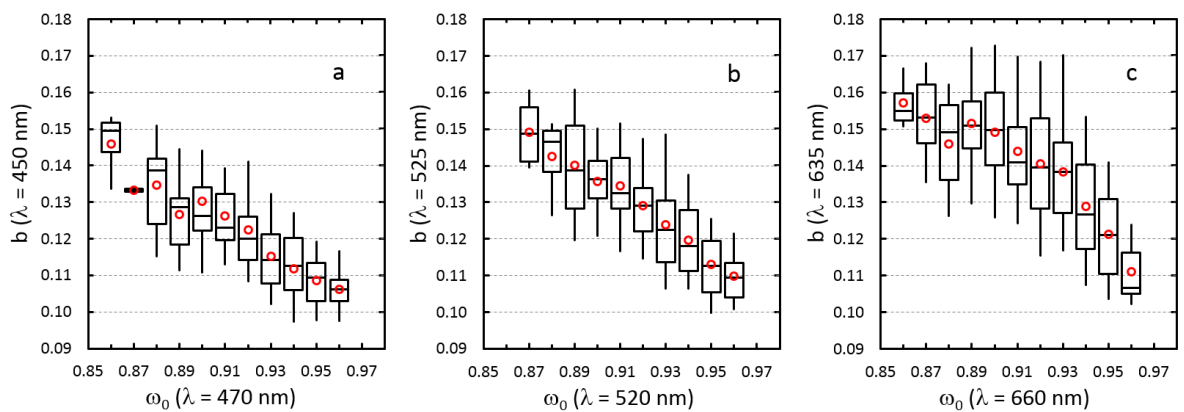

Figure 10. Daily averaged backscatter fraction $(b)$ of (a) blue, (b) green and (c) red light classified into 0.01 wide bins of the single-scattering albedo $\left(\omega_{0}\right)$. Note: $b$ is that measured at the nephelometer wavelengths 450,525 and $635 \mathrm{~nm}$ and $\omega_{0}$ is that at the aethalometer wavelengths 470,520 and $660 \mathrm{~nm}$. The box plots present the 5th, 25th, 50th, 75th, and 95th percentiles and the circles the averages in each bin.

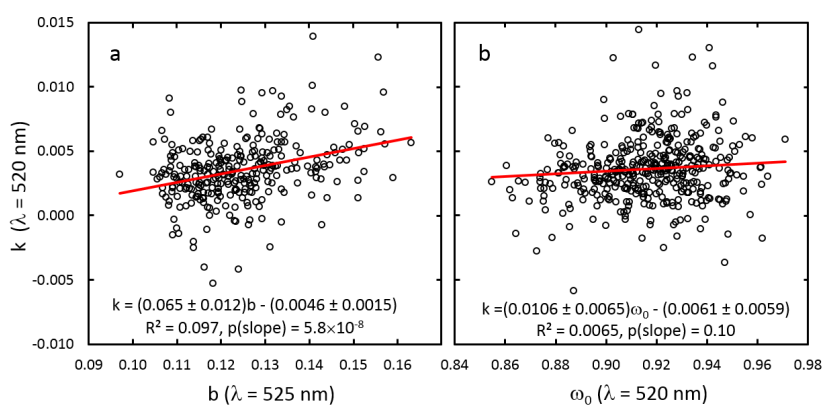

Figure 11. Compensation parameters at the aethalometer green wavelength $(\lambda=520 \mathrm{~nm})$ as a function of (a) the backscatter fraction $b$ and (b) the single-scattering albedo $\omega_{0}$ when $b$ and $\omega_{0}$ were in a narrow range: (a) contains data from those filter changes during which the filter-spot-averaged $\omega_{0}(\lambda=520 \mathrm{~nm})=0.930 \pm 0.005$. (b) contains data from those filter changes during which the filterspot-averaged $b(\lambda=525 \mathrm{~nm})=0.130 \pm 0.005$. The red lines and the equations represent linear regressions fitted to the data.

data available here since $\omega_{0}$ and $b$ were not really independent. The darkest aerosol, i.e., the aerosol with the lowest $\omega_{0}$, was observed when the backscatter fraction was the highest (Fig. 10), suggesting that the particle size of the darkest aerosol was also the smallest.

To disconnect the two effects the data were further classified into (a) a narrow $\omega_{0}$ range $\omega_{0}(\lambda=520 \mathrm{~nm})=0.930 \pm 0.005$ for which linear regressions of $k$ vs. $b$ were calculated and (b) a narrow $b$ range $(b(\lambda=525 \mathrm{~nm})=0.130 \pm 0.005)$ for which linear regressions of $k$ vs. $\omega_{0}$ were calculated. The regressions within these ranges were calculated both for each filter-spot change and for the daily averaged data as above. The linear regressions of the compensation parameters at $\lambda=520 \mathrm{~nm}$ for the individual spot changes are pre presented in Fig. 11 and for the rest of the linear regressions in Tables 3 and 4.

In the individual filter-change regressions there was now a clearly more significant dependence of $k$ on $b\left(p<10^{-4}\right)$ than on $\omega_{0}(p=0.01-0.1)$. For the $k$ vs. $\omega_{0}$ the slope estimates $\beta_{1}$ were actually positive (Table 4 ), meaning that $k$ would increase with increasing $\omega_{0}$, which is just the opposite observation of that made from all the data. The $95 \%$ confidence ranges, on the other hand, include both negative and positive slopes and the $p$ values are high. An exception is the $k$ vs. $\omega_{0}$ at $\lambda=880 \mathrm{~nm}$ : the confidence range is positive and the $\mathrm{p}$ value low. Based on the regression of this one wavelength only it is better not to draw any strong conclusions, however. For the daily averages the $p$ values of most regressions were $>0.1$ and the $95 \%$ ranges had both negative and positive values (Tables 3 and 4), showing that in the daily averaged classified data there was no evidence for the linear relationships of $k$ vs. $b$ and $k$ vs. $\omega_{0}$. There was one exception however, this time $k$ at $\lambda=880 \mathrm{~nm}$ vs. $b$ at $\lambda=635 \mathrm{~nm}$ with $p=0.01$ and the $95 \%$ range of $\beta_{1}>0$.

The above exercise was done to find which one, the singlescattering albedo or the backscatter fraction affects the compensation parameter more. The $p$ values of the individual filter-spot regressions suggest that the effect of the backscatter fraction is more dominant than that of $\omega_{0}$. But since the regressions of the daily averaged data do not show this, it should not be considered proven. To study it in a laboratory, one should produce aerosols that have the same size (and $b$ ) but variable $\omega_{0}$. This is difficult because if variations in $\omega_{0}$ are accomplished by coating pure BC by condensing some scattering material, the particles grow and $b$ decreases.

\subsection{Possible implementation into a data analysis algorithm}

If the relationships between $k, \omega_{0}$, and $b$ were unambiguous aethalometer data could in principle be used in an algorithm for estimating $\omega_{0}$ and $b$. However, as it was shown in the previous section, even after the classifications into $\omega_{0}$ and $b$ bins there was still a large range of compensation parameters that remained unexplained. A probable reason may have been rapidly varying $\mathrm{BC}$ mass concentrations, as mentioned several times above, but there are also other possible explanations.

An important factor missing in the present study is the mixing state of absorbing and scattering aerosols since there 
Table 3. Regression statistics ( $y=\beta_{1} x+\beta_{0}$ ) of compensation parameter vs. backscatter fraction at a limited single-scattering albedo range. Detailed column description as in Table 1 .

\begin{tabular}{|c|c|c|c|c|c|c|c|c|}
\hline \multicolumn{9}{|c|}{ Calculated by using those filter changes during which $\omega_{0}(520 \mathrm{~nm})=0.930 \pm 0.005$} \\
\hline$x$ & $y$ & $r$ & $\beta_{1}$ & SE & $95 \%$ confidence range & d.f. & $t$ & $p$ \\
\hline$b(450)$ & $k(470)$ & 0.24 & 0.051 & 0.012 & $(0.027-0.075)$ & 290 & 4.2 & $3.5 \times 10^{-05}$ \\
\hline$b(525)$ & $k(520)$ & 0.31 & 0.065 & 0.012 & $(0.042-0.089)$ & 290 & 5.6 & $5.8 \times 10^{-08}$ \\
\hline$b(635)$ & $k(660)$ & 0.29 & 0.059 & 0.011 & $(0.037-0.081)$ & 290 & 5.3 & $2.8 \times 10^{-07}$ \\
\hline$b(635)$ & $k(880)$ & 0.36 & 0.101 & 0.015 & $(0.071-0.131)$ & 290 & 6.7 & $1.4 \times 10^{-10}$ \\
\hline \multicolumn{9}{|c|}{ Calculated by using those daily averages during which $\omega_{0}(520 \mathrm{~nm})=0.930 \pm 0.005$} \\
\hline$x$ & $y$ & $r$ & $\beta_{1}$ & SE & $95 \%$ confidence range & d.f. & $t$ & $p$ \\
\hline$b(450)$ & $k(470)$ & 0.16 & 0.013 & 0.012 & $(-0.011-0.038)$ & 48 & 1.1 & 0.28 \\
\hline$b(525)$ & $k(520)$ & 0.21 & 0.017 & 0.012 & $(-0.007-0.042)$ & 48 & 1.5 & 0.15 \\
\hline$b(635)$ & $k(660)$ & 0.21 & 0.017 & 0.011 & $(-0.005-0.039)$ & 48 & 1.5 & 0.14 \\
\hline$b(635)$ & $k(880)$ & 0.36 & 0.043 & 0.016 & $(0.011-0.076)$ & 48 & 2.7 & 0.01 \\
\hline
\end{tabular}

Table 4. Regression statistics $\left(y=\beta_{1} x+\beta_{0}\right)$ of compensation parameter vs. single-scattering albedo at a limited backscatter fraction range. Detailed column description as in Table 1 .

\begin{tabular}{cccccccccc}
\hline \multicolumn{1}{c}{ Calculated by using those filter changes during which $b(525 \mathrm{~nm})=0.130 \pm 0.005$} \\
$x$ & $y$ & $r$ & $\beta_{1}$ & SE & $95 \%$ confidence range & d.f. & $t$ & $p$ \\
\hline$\omega_{0}(470)$ & $k(470)$ & 0.08 & 0.009 & 0.006 & $(-0.002-0.021)$ & 411 & 1.7 & 0.10 \\
$\omega_{0}(520)$ & $k(520)$ & 0.08 & 0.011 & 0.006 & $(-0.002-0.023)$ & 411 & 1.6 & 0.10 \\
$\omega_{0}(660)$ & $k(660)$ & 0.09 & 0.014 & 0.008 & $(-0.001-0.029)$ & 411 & 1.9 & 0.06 \\
$\omega_{0}(880)$ & $k(880)$ & 0.13 & 0.024 & 0.009 & $(0.006-0.043)$ & 411 & 2.6 & 0.01 \\
\hline
\end{tabular}

\begin{tabular}{cccccccccc}
\hline \multicolumn{8}{c}{ Calculated by using those daily averages during which $b(525 \mathrm{~nm})=0.130 \pm 0.005$} \\
$x$ & $y$ & $r$ & $\beta_{1}$ & SE & $95 \%$ confidence range & d.f. & $t$ & $p$ \\
\hline$\omega_{0}(470)$ & $k(470)$ & 0.04 & -0.002 & 0.008 & $(-0.018-0.013)$ & 66 & -0.3 & 0.77 \\
$\omega_{0}(520)$ & $k(520)$ & 0.03 & -0.002 & 0.009 & $(-0.020-0.015)$ & 66 & -0.2 & 0.80 \\
$\omega_{0}(660)$ & $k(660)$ & 0.05 & 0.004 & 0.010 & $(-0.015-0.024)$ & 66 & 0.4 & 0.68 \\
$\omega_{0}(880)$ & $k(880)$ & 0.18 & 0.017 & 0.012 & $(-0.006-0.041)$ & 66 & 1.5 & 0.14 \\
\hline
\end{tabular}

was no method available to measure it. It is likely that the same amount of absorbing aerosol such as BC yields different compensation parameters when it is internally mixed with scattering material and when these two are externally mixed. In these cases the penetration depths of $\mathrm{BC}$ particles into the filter would be different even if the overall backscatter fraction of the aerosol were the same. Therefore it is not likely there will be an unambiguous relationship between $k, \omega_{0}$, and $b$. However, for internally mixed, typical aged BC aerosol, future research may prove out that the relationship is simple enough to be implemented into an algorithm.

\section{Summary and conclusions}

Aerosol optical properties were measured with a sevenwavelength aethalometer and a three-wavelength nephelometer at the suburban site SORPES in Nanjing, China, in September 2013-January 2015. The most important result obtained from the analysis of the data is that quantities calculated from two independent methods; i.e., the backscatter fraction measured with the nephelometer and the compensation parameter $k$, calculated from the aethalometer data with the Virkkula et al. (2007) algorithm, were correlated. At $\lambda=660 \mathrm{~nm}$ the daily averaged compensation parameter $k \approx 0.0017 \pm 0.0002$ and $0.0042 \pm 0.0013$ when the backscatter fraction at $\lambda=635 \mathrm{~nm}$ was in the ranges of $0.100 \pm 0.005$ and $0.160 \pm 0.005$, respectively. Also, the wavelength dependency of the compensation parameter depended on the backscatter fraction: when $b(\lambda=525 \mathrm{~nm})$ was less than approximately 0.13 the compensation parameter decreased with wavelength and at larger $b$ it increased with wavelength. This dependency has not been considered in any of the algorithms that are currently used for processing aethalometer data. The compensation parameter also depended on the single-scattering albedo $\omega_{0}$ so that $k$ decreased with increasing $\omega_{0}$. For the green light $(\lambda=520 \mathrm{~nm})$ in the $\omega_{0}$ range $0.870 \pm 0.005$, the average ( \pm standard deviation) $k \approx 0.0047 \pm 0.006$ and in the $\omega_{0}$ range $0.960 \pm 0.005$, $k \approx 0.0028 \pm 0.0007$. This difference was larger for the nearinfrared light $(\lambda=880 \mathrm{~nm})$ : in the $\omega_{0}$ range $860 \pm 0.005$, $k \approx 0.0055 \pm 0.0023$ and in the $\omega_{0}$ range $0.960 \pm 0.005$, $k \approx 0.0019 \pm 0.0011$. The negative dependence on $\omega_{0}$ was also shown with a simple theoretical analysis.

The interpretation of the above results is complicated by the fact that $b$ and $\omega_{0}$ were not independent: the particles with 
the lowest single-scattering albedo had the highest backscatter fractions. An attempt was made to separate the effects of these two parameters. The selection of one narrow $\omega_{0}$ bin and classifying the compensation parameters again as a function of $b$ and the selection of a narrow backscatter fraction bin and classifying the compensation parameters again as a function of $\omega_{0}$ suggests that $b$ may be even more important a factor than $\omega_{0}$. However, even after classifying the compensation parameters into $\omega_{0}$ and $b$ bins there was still a large range of compensation parameters that remained unexplained. In addition to rapidly varying concentrations a possible explanatory factor is the mixing state of the aerosols that was not measured.

In spite of the uncertainties, the most important conclusion is that the backscatter fraction of the aerosol has a very clear effect on the aethalometer data and it should be taken into account. To quantify this in terms of $\sigma_{\mathrm{a} p}$ or BC mass concentrations, assume that $b=0.16$ and that $\mathrm{ATN}=80$, a typical value for the red wavelength prior to filter spot change. The above average $k$ for the red wavelength yield for the whole compensation function $f=1+k \mathrm{ATN} \approx 1.34$. This means that without the compensation the $\mathrm{BC}$ mass concentration or the absorption coefficient may be even tens of percent too low.

The underlying reasons for the effect of the backscatter fraction are the variations in the enhanced scattering due to variations in the asymmetry parameter and variations in the penetration depth of the particles into the filter, which depend on their size. This observation is important especially in China where anthropogenic pollution is often mixed with desert dust: the backscatter fraction is large for small particles and small for large particles such as soil dust.

Another, related conclusion is that also the multiplescattering correction factor $C_{\text {ref }}$ may potentially be a function of both $b$ and $\omega_{0}$. Collaud Coen et al. (2010) found that $C_{\text {ref }}$ decreased with increasing $\omega_{0}$. But they also found that $C_{\text {ref }}$ varied considerably even at one measurement site and hypothesized that it might be due to semi-volatile organic compounds and water vapor condensing on the filter fibers or to other similar phenomena. In the present study, neither a new $C_{\text {ref }}$ nor any algorithm for getting the absorption coefficient was even attempted to be derived due to a lacking independent absorption method. In the future this should be done by using for instance an extinction instrument or a photoacoustic spectrometer together with the aethalometer and the nephelometer. Ideally, the measurement setup would also contain a method for measuring the mixing state of the aerosol, for instance an SP2 instrument or a Volatility Tandem Differential Mobility Analyzer (VTDMA). If it turns out that $C_{\text {ref }}$ also depends on the backscatter fraction and the single-scattering albedo in a predictable way, then the relationships between $k$, $b$, and $\omega_{0}$ could in principle also be used for estimating $C_{\text {ref. }}$.

This study was conducted by analyzing data collected with the AE31 aethalometer model, which uses a different filter material and the flow setup than the new AE33 aethalometer model. Also, the compensation factor is calculated there in a slightly different way, but it was shown above that in principle the difference is not big. Therefore the results presented above will most probably not be quantitatively the same, but it is very likely that the qualitative results are the same: the larger the backscatter fraction is, the larger are the compensation parameter and the slope of the wavelength dependency on it, and the other way around when comparing with the single-scattering albedo. This can be considered as a recommendation for future research.

\section{Data availability}

To obtain the data used in the paper, please contact the corresponding author.

Acknowledgements. The research was supported by the Jiangsu Provincial Natural Science Fund (no. BK20140021), National Science Foundation of China (D0510/41275129), and Academy of Finland's Centre of Excellence program (Centre of Excellence in Atmospheric Science - From Molecular and Biological processes to The Global Climate, project no. 272041).

Edited by: W. Maenhaut

\section{References}

Andrews, E., Sheridan, P. J., Fiebig, M., McComiskey, A., Ogren, J. A., Arnott, P., Covert, D., Elleman, R., Gasparini, R., Collins, D., Jonsson, H., Schmid, B., and Wang, J.: Comparison of methods for deriving aerosol asymmetry parameter, J. Geophys. Res.-Atmos., 111, D05S04, doi:10.1029/2004JD005734, 2006.

Arnott, W. P., Hamasha, K., Moosmuller, H., Sheridan, P. J., and Ogren, J. A.: Towards aerosol light-absorption measurements with a 7-wavelength aethalometer: evaluation with a photoacoustic instrument and 3-wavelength nephelometer, Aerosol Sci. Tech., 39, 17-29, doi:10.1080/027868290901972, 2005.

Cheng, Y.-H. and Yang, L.-S.: Correcting aethalometer black carbon data for measurement artifacts by using inter-comparison methodology based on two different light attenuation increasing rates, Atmos. Meas. Tech. Discuss., 8, 2851-2879, doi:10.5194/amtd-8-2851-2015, 2015.

Collaud Coen, M., Weingartner, E., Apituley, A., Ceburnis, D., Fierz-Schmidhauser, R., Flentje, H., Henzing, J. S., Jennings, S. G., Moerman, M., Petzold, A., Schmid, O., and Baltensperger, U.: Minimizing light absorption measurement artifacts of the Aethalometer: evaluation of five correction algorithms, Atmos. Meas. Tech., 3, 457-474, doi:10.5194/amt-3457-2010, 2010.

Ding, A. J., Fu, C. B., Yang, X. Q., Sun, J. N., Zheng, L. F., Xie, Y. N., Herrmann, E., Nie, W., Petäjä, T., Kerminen, V.-M., and Kulmala, M.: Ozone and fine particle in the western Yangtze River Delta: an overview of $1 \mathrm{yr}$ data at the SORPES station, Atmos. Chem. Phys., 13, 5813-5830, doi:10.5194/acp-13-58132013, 2013a. 
Ding, A. J., Fu, C. B., Yang, X. Q., Sun, J. N., Petäjä, T., Kerminen, V.-M., Wang, T., Xie, Y., Herrmann, E., Zheng, L. F., Nie, W., Liu, Q., Wei, X. L., and Kulmala, M.: Intense atmospheric pollution modifies weather: a case of mixed biomass burning with fossil fuel combustion pollution in eastern China, Atmos. Chem. Phys., 13, 10545-10554, doi:10.5194/acp-1310545-2013, 2013b.

Drinovec, L., Močnik, G., Zotter, P., Prévôt, A. S. H., Ruckstuhl, C., Coz, E., Rupakheti, M., Sciare, J., Müller, T., Wiedensohler, A., and Hansen, A. D. A.: The "dual-spot" Aethalometer: an improved measurement of aerosol black carbon with realtime loading compensation, Atmos. Meas. Tech., 8, 1965-1979, doi:10.5194/amt-8-1965-2015, 2015.

Heal, M. R. and Hammonds, M. D.: Insights into the composition and sources of rural, urban and roadside carbonaceous $\mathrm{PM}_{10}$, Environ. Sci. Technol., 48, 8995-9003, 2014

IPCC: Climate Change 2013: the Physical Science Basis, contribution of Working Group I to the Fifth Assessment Report of the Intergovernmental Panel on Climate Change, edited by: Stocker, T. F., Qin, D., Plattner, G.-K., Tignor, M., Allen, S. K., Boschung, J., Nauels, A., Xia, Y., Bex, V., and Midgley, P. M.: Cambridge University Press, Cambridge, UK and New York, NY, USA, 1535 pp., 2013.

Lack, D. A., Cappa, C. D., Cross, E. S., Massoli, P., Ahern, A. T., Davidovits, P., and Onasch, T. B.: Absorption enhancement of coated absorbing aerosols: validation of the photo-acoustic technique for measuring the enhancement, Aerosol Sci. Tech., 43, 1006-1012, doi:10.1080/02786820903117932, 2009.

Moteki, N., Kondo, Y., Nakayama, T., Kita, K., Sahu, L., Ishigai, T., Kinase, T., and Matsumi, Y.: Radiative transfer modeling of filter-based measurements of light absorption by particles: importance of particle size dependent penetration depth, J. Aerosol Sci., 41, 401-412, doi:10.1016/j.jaerosci.2010.01.004, 2010.

Müller, T., Laborde, M., Kassell, G., and Wiedensohler, A.: Design and performance of a three-wavelength LED-based total scatter and backscatter integrating nephelometer, Atmos. Meas. Tech., 4, 1291-1303, doi:10.5194/amt-4-1291-2011, 2011.

Müller, T., Virkkula, A., and Ogren, J. A.: Constrained two-stream algorithm for calculating aerosol light absorption coefficient from the Particle Soot Absorption Photometer, Atmos. Meas. Tech., 7, 4049-4070, doi:10.5194/amt-7-4049-2014, 2014.

Nakayama, T., Kondo, Y., Moteki, N., Sahu, L. K., Kinase, T., Kita, K., and Matsumi, Y.: Size-dependent correction factors for absorption measurements using filter-based photometers: PSAP and COSMOS, J. Aerosol Sci., 41, 333-343, 2010.

Park, S. S., Hansen, A. D. A., and Cho, Y.: Measurement of real time black carbon for investigating spot loading effects of Aethalometer data, Atmos. Environ., 11, 1449-1455, doi:10.1016/j.atmosenv.2010.01.025, 2010.
Putaud, J.-P., Dingenen, R. V., Alastuey, A., et al.: A European aerosol phenomenology - 3: physical and chemical characteristics of particulate matter from 60 rural, urban, and kerbside sites across Europe, Atmos. Environ., 44, 1308-1320, doi:10.1016/j.atmosenv.2009.12.011, 2010.

Schmid, O., Artaxo, P., Arnott, W. P., Chand, D., Gatti, L. V., Frank, G. P., Hoffer, A., Schnaiter, M., and Andreae, M. O.: Spectral light absorption by ambient aerosols influenced by biomass burning in the Amazon Basin. I: Comparison and field calibration of absorption measurement techniques, Atmos. Chem. Phys., 6, 3443-3462, doi:10.5194/acp-6-3443-2006, 2006.

Segura, S., Estellés, V., Titos, G., Lyamani, H., Utrillas, M. P., Zotter, P., Prévôt, A. S. H., Močnik, G., Alados-Arboledas, L., and Martínez-Lozano, J. A.: Determination and analysis of in situ spectral aerosol optical properties by a multi-instrumental approach, Atmos. Meas. Tech., 7, 2373-2387, doi:10.5194/amt-72373-2014, 2014.

Shen, Y., Chi, X., Ding, A., Nie, W., Qi, Zheng, L., Huang, X., Xie, Y., Wang, J., Virkkula, A., Petäjä, T., and Kulmala, M.: Seasonal and diurnal cycles of in situ aerosol optical properties at the SORPES station in Nanjing, China, Atmos. Chem. Phys., in preparation, 2015.

Song, S., Wu, Y., Xu, J., Ohara, T, Hasegawa, S., Li, J., Yang, L., and Hao, J.: Black carbon at a roadside site in Beijing: temporal variations and relationships with carbon monoxide and particle number size distribution, Atmos. Environ., 77, 213-221, 2013.

Virkkula, A., Mäkelä, T., Yli-Tuomi, T., Hirsikko, A., Koponen, I. K., Hämeri, K., and Hillamo, R.: A simple procedure for correcting loading effects of aethalometer data, J. Air Waste Manage., 57, 1214-1222, doi:10.3155/1047-3289.57.10.1214, 2007.

Wang, Y., Hopke, P. K., Rattigan, O. V., Xia, X., Chalupa, D. C., and Utell, M. J.: Characterization of residential wood combustion particles using the two-wavelength aethalometer, Environ. Sci. Technol., 45, 7387-7393, 2011.

Weingartner, E., Saathoff, H., Schnaiter, M., Streit, N., Bitnar, B., and Baltensperger, U.: Absorption of light by soot particles: determination of the absorption coefficient by means of aethalometers, J. Aerosol Sci., 34, 1445-1463, 2003.

WMO: WMO/GAW Aerosol Measurement Procedures Guidelines and Recommendations, WMO TD No. 1178 - GAW Report No. 153, World Meteorological Organization, Geneva, Switzerland, 2003. 